Emotional Transitions? Exploring the Student Experience of Entering Higher Education in a Widening-Participation HE-in-FE Setting

Dr Emma Young (corresponding author)

E.young2@bradford.ac.uk

$+441274232627$

Affiliation: University of Bradford

Richmond Road

Bradford

BD7 1DP

Mrs Rachael Thompson

+441613448857

Affiliation: University Campus Oldham

Academic Success Centre

Professor John Sharp

+441138123052

Affiliation: University of Lincoln

Lincoln Higher Education Research Institute (LHERI)

Dr Daniel Bosmans

+441613448808

Affiliation: University Campus Oldham

Academic Success Centre 


\section{Disclosure Statements}

I confirm that there is no financial interest or benefit I have arising from the direct applications of this research. Emma Young

I confirm that there is no financial interest or benefit I have arising from the direct applications of this research. Rachael Thompson

I confirm that there is no financial interest or benefit I have arising from the direct applications of this research. John Sharp.

I confirm that there is no financial interest or benefit I have arising from the direct applications of this research. Daniel Bosmans

\section{Notes on Contributors}

Dr Emma Young is Head of Student Success Services at the University of Bradford.

Previously, she worked as Head of Student Journey at University Campus Oldham, as an Academic Development Lecturer and a Lecturer in English Literature at universities across the UK. Her research includes an edited collection, a monograph and multiple book chapters and journal articles on women's writing and feminist politics as well as more recent work on Peer Assisted Learning and student academic boredom in HE.

Rachael Thompson is a Psychology Technician and Academic Development Lecturer at University Campus Oldham. Having recently completed an MRes, she is now studying for her Ph.D at the University of Huddersfield. Her own research interests surround psychology concepts relating to crime, as well as exploring factors within HE that influence the student experience and their anxiety. She actively attends conferences, presenting work at the British 
Conference for Undergraduate Research in 2016, and has submitted her dissertation project for publication.

Professor John Sharp is Professor of Higher Education and Head of the Lincoln Higher Education Research Institute (LHERI) at the University of Lincoln, which specialises in the evaluation of educational interventions and their impact at a variety of levels as well as providing support in the fields of Higher Education research and practice to staff and students across the university and beyond. His work on student engagement has led to the development of new lines of enquiry in the field of academic boredom and its effects across the teachinglearning environment with implications for course design and delivery as well as how students are supported in their studies.

Dr Daniel Bosmans is an Academic Development Lecturer at University Campus Oldham. He has taught ESOL/EFL/EAP at various universities and colleges across the Northwest of England. He has also taught French online for 14 years and has contributed to the 3 new books for this course, as well as the online pronunciation guide used by the students. His research interests encompass metacognition and affect in language learning, phonology, peerassisted learning and learning strategies. Publications include journal articles and conference papers on all these topics.

\section{Geolocalisation}

This study was conducted at University Campus Oldham, University Way, Oldham, OL1 1BB. The coordinates are $* 53.5386^{\circ} \mathrm{N}, 2.1138^{\circ} \mathrm{W}^{*}$. 


\section{Acknowledgements}

We owe a debt of gratitude to the first-year learners who study at University Campus Oldham.

They gave up time to take part in various stages of the study and without whom there would have been no data to analyse. 
Young, Thompson, Sharp \& Bosmans 5 


\title{
Emotional Transitions? Exploring the Student Experience of Entering Higher Education in a Widening-Participation HE-in-FE Setting
}

\begin{abstract}
This paper details a small-scale research project that explores the student transition into higher education (HE), delivered in a further education college (FE), and considers whether the requirements of transition at this level impacts on emotional wellbeing. As such, it aims to contribute to the growing body of research on HE-in-FE from the perspective of student transition and emotional wellbeing. The data drawn on in this paper was collected by a questionnaire, administered at two points in the first semester, to measure levels of anxiety in students, alongside a further questionnaire designed to evaluate the effectiveness of bespoke academic skills input aimed at supporting the transition into HE. From quantitative and qualitative data, key findings identify factors that influence students' emotional responses to HE, including those that exacerbate and those that mitigate negative emotional responses. Significantly, the research identifies academic factors, rather than personal or social issues, as being critical to students' emotional experiences during the transitionary period.
\end{abstract}

Keywords: Emotion, Transition, Widening Participation, HE in FE, Well-being

\section{Introduction}

In recent years, increased attention has been afforded to concerns surrounding higher education (HE) students' mental health and psychological and emotional wellbeing. The prevalence of these issues is discussed in a body of research, which acknowledges that studying at university is a notably anxious time for many students (Barkham et al. 2006; Bewick et. al. 2010), with recent focus shifting to the rise in the number of student suicides in 
higher education across England and Wales (Office for National Statistics 2018; Smith and Howie 2018; Universities UK 2015; Mallon, Manthrope and Stanley 2009). The expectations set out by HE study, and the demands placed on the individual, have been often cited as causing increased levels of anxiety and stress (Chambers and Hassed 2014; Irwin, Miller and Nigh 2014; Martin and Richards 2012; Beanlands et al. 2017; Smalley and Winston 2010). Following the Higher Education Act (2004), universities in England could charge up to $£ 3,000$ per year in tuition fees which, following the Browne Review (2010), rose to up to $£ 9,000$ per year. In 2016 in England (where the institution in this case study is based), student funding for higher education underwent a shift and saw grants being replaced by maintenance loans, meaning for many students an increase in debt after graduation (Belfield, Britton, Dearden and van de Erve 2017). Residing alongside an ambition to widen participation with HE, it would seem students are entrapped in a complex paradox in which they are actively encouraged to undertake a degree while being charged more for then choosing to do so. The issue of debt has been documented as one that disadvantages those from a widening participation background and possible reason why students do not undergo HE study (Clark \& Hordosy, 2018; Budd, 2017; Harrison \& Hatt, 2012). Potentially, this risks exacerbating an already anxious moment in their educational and personal development.

Furthermore, the transitionary period is acknowledged as being crucial to students' emotional and mental wellbeing, with research showing that the first year of study is especially challenging for students, with the adjustment to independent learning after the structured learning environments of their schools often being problematic (Abrahams et al. 2016). Consequently, studies have not only shown higher stress levels for undergraduate students compared with the general population (Adlaf et al. 2001; Roberts and Zelenyanski 2002; Balding 2000), but have pinpointed the first semester of the first year as the period 'where anxiety is one of the most elevated items' (Barkham et al. 2006, 514). Gudykunst 
(2005, 286-287) defines anxiety as 'the affective (emotional) equivalent of uncertainty. We experience some degree of uncertainty any time we communicate with others ... It stems from feeling uneasy, tense, worried or apprehensive about what might happen'. With the transition into a new educational environment being an uncertain time of new demands and expectations for students, it is unsurprising that anxiety should be identified as a key concern for current students.

This small-scale research project draws on the experiences of students in a HE-in-FE institution, which engages with student who hold widening participation characteristics all of whom are commuter and from diverse socio-economic and ethnic backgrounds. For the purposes of this study it is important to establish some key definitions. Firstly, students with widening participation characteristics meet one or more of the following criteria: come from a lower socioeconomic background, live in a low education participation postcode, are first generation students or mature students, or enter HE with non-traditional qualifications. With the overall student demographic in 2017-18 including 56\% students over the age of $25,82 \%$ coming from POLAR 1-3 (lowest educational participation areas) and 87\% classed as National IMD (Indices of Multiple Deprivation) 1-2, the overall institutional profile can be considered as widening participation. Furthermore, HE-in-FE refers to higher education delivered in a further education college in the UK. The degree courses are all validated by partner Universities, but students' study for their entire degree (including Level 6) at the local college. For most students this is a conscious choice because it enables them to stay close to their families and/or existing personal commitments. Finally, in referring to anxiety and measuring it through the questionnaire instrument, this research takes into account two main types of anxiety: trait and state: 'trait anxiety (a personality characteristic more or less permanent) and state anxiety (a temporary emotion felt at a particular moment in a given situation)' (Ellis 2008, 691). 
In this institutional and social context, supporting the student transition can be a unique challenge. While previously identified sources of student anxiety (such as homesickness) become less relevant, nonetheless, financial difficulties, balancing family and/or work commitments with HE study, and prior academic experience emerge as far more salient factors to consider in relation to the transition into and through a degree course. There can be detrimental consequences instigated by academic anxiety, with Bradley (2017) identifying this as another major cause of students thinking about quitting their degree course. Thus, anxiety not only effects the initial transition into HE but has potential ramifications for student retention and success rates. The aim of this exploratory case study is to investigate potential causes of student anxiety in a HE-in-FE institution, drawing on qualitative and quantitative data alongside practitioner experience, and to use this illustratively to shed light on the factors that help mitigate student anxiety during the transition period in order to suggest recommendations for good practice in addressing potential barriers. As such, it aims to contribute to the growing body of research on HE-in-FE from the perspective of student transition and emotional wellbeing. The literature review considers relevant research on both the student transition into $\mathrm{HE}$ as well as current discussions on students' mental and emotional wellbeing. Both of these fields underpin the current study and are integral to the research methods and ensuing discussion. In the process, three underpinning questions are pursued in this article: Does the transition into HE effect levels of anxiety in students? If student emotions change within the first semester of the first year, what happens? What factors influence student emotions in response to the HE transition and how can institutions and practitioners help mitigate negative factors? 


\section{Transition into $\mathrm{HE}$}

The student experience during the transition period into HE study is a well-trodden area of discussion, with an increasing body of literature focusing on the relationship between transition and wellbeing. It is long-recognised that during the transition period students are confronted with significant changes and new challenges whether these be personal, social or academic. Furthermore, adjustment during the transition has been linked with the student's own emotional intelligence, relating to their ability to monitor and understand both their own feelings and the emotions of others (Porche, 2016; Caruso, Mayer \& Salovey, 2004), and selfefficacy (Watson \& Watson 2016), as well as an individual's ability to cope with stress (Aspinwall and Taylor 1992; Van Rooijen 1986). Results of a study by Baker (2003, 583) suggest that an individual's social problem-solving capacity was a strong indicator for predicting their 'psychosocial adjustment to university, perceived stress levels, motivational orientations (identified extrinsic motivation and amotivation), and academic performance whilst studying'. Emotions, especially stress and the ability to cope with that stress, have clear repercussions in terms of a student's overall achievement and subsequent success into, through and beyond HE study. Christie, Cree, Hounsell, McCune and Tett (2008, 135) conclude that 'emotions such as fear, resentment and guilt, as well as enthusiasm, excitement and pride, all infuse choice-making processes and help to explain the diversity of pathways young people take to higher education'. The emotions experienced as part of the transition into higher education study still requires further exploration, particularly in an $\mathrm{HE}$ in FE context where factors impacting on students' emotions will be different than in a more traditional university environment.

Research also highlights why the transition is of fundamental importance to the institution as much as it is to the individual. The failure to make a satisfactory transition into university life, shaped by meeting the new academic and social demands this entails, often 
results in student under-achievement, or more seriously, student drop-out (Cook and Lowe 2003; Bradley 2017). Importantly, it is those students who often exist 'under the radar', who do not speak out about the difficulties encountered with the changes involved in entering HE, who present the most crucial challenge for universities (Cook and Lowe 2003). It has long been noted that the focus of HE on syllabi and autonomous learning results in teaching strategies often overlooking skills development needs and self-directed enquiry (Boud 1988; Cook and Lowe 2003). Thus, the struggle with the transition into university life not only impacts on the individual and their success, but it has potentially negative implications for the institution as well.

In a widening participation context, the transition period can be even more complex, raising a unique set of issues and challenges for these students. As Christie (2009) notes, student identities have moved beyond that of the white middle-class individual and there is now an increasing array of pathways into HE. In particular, Keane (2011) questions how the education system might better support working class students, highlighting that confidence levels are a key area to address. Moreover, data shows shifts in the habits of the student population as there has been a significant rise in the number of students living at home and commuting to a local institution, with many of these being mature students. (UCAS 2000; Holdsworth and Patiniotis 2005). In terms of anxiety and the transition into HE, Murphy and Roopchand (2003) suggest that the mature student is likely to be more anxious and less confident than the traditional student as they are often unable to measure themselves against earlier, successful academic study. Accordingly, in thinking about the widening participation student, issues of academic confidence and the importance of emotions are clearly key elements of the transitionary experience. 


\section{Students' Mental and Emotional Wellbeing}

Increased social awareness of mental health and emotional wellbeing issues has led to greater attention being paid to these matters in academia and the student population. While some of the research that centres on within-population participants has tended to focus on identifying the causes of stress for students (Grant 2002; Tyrell 1992), other research has investigated the relationship between stress triggers and student mental health (Andrews and Wilding 2004; Monk 2004). Additionally, the impact of stress on a student's quality of life has also been examined (Boery, Casotti, Freire, de Oliveira, Pereira and Riberiro. 2018). In an earlier study, Barkham et. al. $(2010,641)$ found that 'the levels of strain are generally highest during semester one, with significant reduction in levels of psychological distress from semester one to semester two being observed in year one and year three'. Thus, the immediate period of transition (first semester of the first year) has been identified as the most critical point in regards to students' emotional responses to transition into HE. Thinking about widening participation factors, as Christie (2009) summarises, existing studies highlight the emotional implications of navigating financial, social and cultural barriers into and through university. Moreover, Christie stresses that, for the WP student, 'the transition to university is an intensely emotional process' and one which is shaped by conflicting and paradoxical feelings in regards to "fitting in" to student life' (Christie 2009, 125). Arguably, these studies all point to the need to further understand the emotion-based reactions that may be provoked by this experience.

The causes of student anxiety in HE can be conceptualised as being one of two sources: intrinsic or extrinsic. That said, the two are clearly interwoven with intrinsic factors, such as attitude towards study and indeed motivation for study, being shaped, either consciously or unconsciously, by wider socio-economic discourses. Nonetheless, intrinsic factors like student attitude towards activities which put at risk one's own skills and abilities, 
or in simpler terms, the fear of failure, are significant influences on how students feel about their HE pursuits. At the same time, the skills and academic abilities of the individual student can also contribute to emotional responses. For example, good time management has been shown to help students avoid academic stress (Misra and McKean 2000). A further intrinsic source of anxiety lies in an individual's personal traits. For example, shyness can result in difficulties with making new friends and interacting in a new environment thereby meaning personality characteristics can also be a possible source of negative emotional responses to engaging in HE level study.

With recent, rapid changes to the HE sector, arguably extrinsic sources of anxiety are becoming far more prevalent in the current student population. Graduates have to face stiff competition in the job market when they complete their studies and thus increasingly view their degree as a commodity that they need to invest in, but which will hopefully lead to employment. Such a view is longstanding, with Friedman (1955, 8, as seen in Morris 2017) having viewed education as 'a form of investment in human capital precisely analogous to investment in machinery, buildings, or other forms of non-human capital'. The outcome that means this investment will "pay off" is a good first degree. The pressure to achieve this and to "fulfil their potential" can cause significant emotional stress for an individual and result in increased levels of anxiety. In a data-driven HE market, the external discourses of excellence, success and achieving the correct 'graduate destination' place a new onus on students which foregrounds a consumer-capitalist approach to HE, which could result in greater emotional strain on some individuals.

In the traditional university environment, in which students leave the parental home and live independently, living arrangements and the changes in routine can often be causes of stress (Heckert, Niebling and Shannon 1999). Such extrinsic factors are succinctly summarised by Barkham et al. (2006, 506): 'Academic, relationship and financial difficulties 
have been found to be some of the major causes of stress for students (Grant, 2002) and relationships between these variables and mental health have also been found (e.g. Andrews \& Wilding, 2004; Monk, 2004; Roberts \& Zelenyanski, 2002)'. Although most students take a loan to finance their studies, as well as accommodation and living expenses, this is somewhat different in an HE-in-FE institution where students usually live in close proximity to their place of study. Nonetheless, the loan they take to finance their study may still be a source of great anxiety. In an economically-deprived area, or for returning students with caring and additional personal demands, the student loan often becomes a means of supporting the student as well as dependants during the period of study. Additionally, such students often have further commitments pertaining to part-time work which exacerbate timerelated demands and the challenge of self-organized learning that many university students battle with (Hafner, Oberst and Stock 2015). Seemingly, there are a wide range of extrinsic sources of anxiety for students that can all contribute to negative emotional responses to undertaking HE study.

As far as research that examines ways in which institutions and practitioners can support students in mitigating negative emotions and sources of anxiety, Bore et. al. (2016) propose the incorporation of resilience training in the university curriculum has some potential to alleviating the prevalence and levels of distress that students might experience. Similarly, a project by Beanlands et. al. (2017) introduced mindfulness practice into the classroom with results showing decreased levels of stress and anxiety in students. These more recent studies chime with the well-established work of Duckworth and Dweck in relation to grit, resilience and growth mindset, with Duckworth defining grit as 'passions and persistence for long-term goals' (Duckworth \& Quinnn 2009, p.166) and believing that grit could be achieved through a "growth mindset”. Similarly, Dweck's work $(1999,2007)$ examines how a fixed belief in failure, or a fixed mindset, could prevent students from academic success and 
theorises how this can be overcome by embracing a "growth mindset" approach that views abilities and intelligence as being developed by the individual. Thus, the focus of much research on student mental and emotional wellbeing to-date has centred on wider life skills and personal development within students (intrinsic mitigating factors). Moreover, the fact that research highlights that there are multiple periods of time during their degree when students experience increased levels of psychological distress suggests that there could be a need to develop a range of support and intervention packages dependent on the trigger factors at any one time (Barkham et. al. 2010).

Given the ebb and flow of students' emotional responses to HE study, this research project focuses purely on the first semester of the first year to provide greater understanding as to how students experience the initial transition into HE and what impact this might have on their emotions and wellbeing. Crucially, this research explores students' perception and understanding as to their own emotional responses while investigating factors that may increase and/or decrease student anxiety levels during the first semester. Such research recognises that the student journey can be a tumultuous one with various challenges, but, critically, aims to understand more specifically what students perceive those challenges to be in order to support the development of coping strategies and improve the management of their studies.

\section{Methods}

\section{Ethics}

Ethical standards were upheld by adhering to the guidance of the Ethics Committee of the British Psychological Society (2009) in relation to informed consent. As such, there was verbal communication with students to outline the research aims and a clear explanation that participation was voluntary. Students were informed that they had the right to withdraw at any 
point and that all data would be anonymised and kept secure. The act of questionnaire completion was non-compulsory.

\section{Participants}

The research was conducted in an HE-in-FE institution in the North-West of England which had a total student population of 582 in the $2016 / 17$ academic year, comprised of $68 \%$ female students to $32 \%$ male students. In terms of ethnicity, the White British to Black Minority Ethnic (BME) statistics are more equally divided with BME students constituting $48 \%$ of the student population; a significant difference to the national population of students in England (excluding London) which in 2015 recorded an overall BME population of 18.4\% (Equality Challenge Unit, 2014a). Notably, the institution has a higher than average mature student, or "adult-returner" population with $71 \%$ being aged 21 or over compared to a national average of $45 \%$ aged 22 or over (Equality Challenge Unit, 2014b). Therefore, this research focuses on a niche within the $\mathrm{HE}$ sector and involves understanding the student experiences at a distinctly widening-participation institution, as can be seen in Table $1^{\mathrm{I}}$.

<Table 1 to be placed about here>

The study utilised an opportunity sampling method with the inclusion criteria for the research being all first-year students enrolled on a degree programme at the institution at Level 4. All questionnaires were distributed during scheduled teaching sessions by the Academic Development team with voluntary participation. The first questionnaire (see Appendix 1) was made up of two parts: a Y-6 self-evaluation and the GAD-7 (which asked students to reflect on the last two weeks in their responses). The second questionnaire comprised the Y-6 item along with three open questions asking participants to elaborate on their emotions and 
experiences, including identifying factors (see Appendix 2). This captured qualitative data to enhance the quantitative analysis. Administering the Y-6 and GAD-7 questionnaire when students started the first semester (between teachings weeks 2-4) provided a baseline for the data set (see Appendix 1), with the second questionnaire being administered towards the end of the first semester (between teaching weeks 9-11). A total of 86 undergraduates completed both of the questionnaires to measure anxiety and after removing responses that were incomplete or contained outliers the final sample size was 60 undergraduate students $(37 \%$ of the eligible population). The third questionnaire evaluating academic skills input was administered in week ten of semester one to provide further qualitative data pertaining to the student transition into HE in relation to academic skills development (see Appendix 3). The sample of students who completed the Y-6 and GAD-7 questionnaire at both time periods can be seen in Table 2 which also shows sample representativeness compared to the whole student cohort. The response rate for the additional questionnaire evaluating academic skills input can be observed in Table 3 .

$<$ Table 2 to be placed about here>

<Table 3 to be placed about here>

\section{Analysis}

The data was analysed through the Statistical Package for the Social Sciences (SPSS). Each of the questions from the questionnaire was converted into a variable and students' responses were then coded on a scale of 1-4, reflecting the questionnaire format. Positive emotion scores were reversed as required by the questionnaire format and qualitative responses were analysed using Nvivo for all questionnaires. In addition, the Y-6 and GAD-7 questionnaires used for 
the study had previously been subjected to Factor analysis thereby ensuring that the questions asked were appropriate to measure the students' anxiety and emotions (See Bekker and Marteau 1992; Tluczek, Henriques and Brown 2009, for the computations run to test reliability and validity of the short version of the STAI).

A Pearson's Chi-Square, implemented to establish how variables relate to one another (Field, 2013), determined that demographic details of participants were broadly typical of the cohort from which they were drawn with respect to age $\left(\aleph^{2}(1)=0.103, p=.749\right)$ and gender $\left(\aleph^{2}(1)=1.100, p=.294\right)$, with BME groups significantly under-represented $\left(\aleph^{2}(1)=10.624\right.$, $\mathrm{p}=.001, \emptyset=.257)$. This can be partially attributed to the low response rate from students on the following courses: Business Management (37\% response vs. $75 \%$ population) Health and Community Studies (67\% response vs. $80 \%$ population) and Psychological Studies (12\% response vs. $44 \%$ population). No missing values or extreme scores were present within the data set. Results from a Kolmogorov-Smirnov test, used to indicate how scores within a dataset compare to normal distribution (Field, 2013), showed assumptions of normality to be broken. Therefore, non-parametric Wilcoxon signed rank tests were applied to the data to investigate whether any significant differences existed within the data set and between participants two collected sets of scores (Field, 2013).

\section{Findings}

Of the 60, 17 students (28\%) self-identified as being generally anxious, based on the responses to the self-evaluation questionnaire (Y-6 item), while the other 43 students (71\%) did not identify themselves to be generally anxious people. Reviewing the entire sample, the Spielberger State-Trait Anxiety Inventory (STAI) (Bekker and Marteau, 1992) reveals that students were less anxious at the end of the first semester $(\mathrm{Mdn}=32)$ than when they first 
started the semester $(\mathrm{Mdn}=35)$ with a non-significant difference existing $(\mathrm{Z}=-2.576, p=$ 0.10 ) between overall anxiety levels of students. The individual emotions contained within the scale were analysed at the start of the semester (see Table 4) and at the end of the semester (see Table 5).

<Table 4 to be placed about here>

$<$ Table 5 to be placed about here>

While the scores report an increase in how worried, tense and upset students feel at this later point in the term, there also appears to be a slight increase in the positive emotions of feeling relaxed, content and calm. As a whole, therefore, there is no single emotional response to the stages of transition with results indicating a complex range of emotional responses.

\section{Students Who Identify as Generally Anxious}

The STAI shows students to be generally classified as anxious with scores being slightly higher than the normal range of 34-36, as defined by the instrument's scale (Bekker and Marteau, 1992). However, students were less anxious at the end of the first semester (Mdn= 36) than when they first started the semester $(\mathrm{Mdn}=40)$ with scores being significantly different, $\mathrm{Z}=-2.282, p=.022$. In terms of individual emotions, Table 6 indicates that while there are some changing statistical outcomes, none are significant enough to draw absolute conclusion or trend. Nonetheless, these results suggest that the transition into HE is a complex experience which results in the coexistence of competing emotional states of being at any one time for individuals. The constant scores of how worried, tense and upset students felt at the end of the semester, compared to at the start of the course, suggests the transition into HE 
may not prove to be as emotionally challenging for those who identify as being generally anxious or that they may withhold coping strategies and methods that enable them to control their anxieties in this new educational environment due to prior experiences. Equally, with assessment points tending to fall at the end of the semester this could also account for the similarity in anxiety levels across the two points.

$<$ Table 6 to be placed about here>

\section{Students Who Do Not Identify as Generally Anxious}

The overall score on the STAI achieved by students sits within the normal range (Bekker and Marteau, 1992). Levels of anxiety remained constant from when students started the first semester to when they finished their first semester $(\mathrm{Mdn}=30)$, with scores being nonsignificant $(\mathrm{Z}=-1.682, p=0.92)$. In regards to individual emotions, again changes can be observed in Table 7 but with significance only becoming apparent for how upset students felt. The increased scores in how worried and tense students felt along with a significant difference existing in how upset students felt, suggests that those students who do not describe themselves as generally anxious may not cope as well as other students who do recognise that they are often generally anxious. This may be due to the fact that they do not self-identify with anxiety and so do not withhold any types of coping mechanisms, unlike the students who are generally anxious. Equally, it may be that these students have not previously engaged in activities that place such demands on their cognitive, social and personal skills as to trigger feelings of anxiety, but that HE is a greater challenge than anticipated. However, the change in emotions implies that, although students do not fall into the classification of 'anxious', they do experience a range of emotional responses to the transition into HE. 
$<$ Table 7 to be placed about here>

\section{Factors that Increase Anxiety}

There was no significant differences between those who self-identify as anxious and those who do not in terms of the factors that either increase or decrease anxiety. Students indicated that the assignments $(x=13)$ and approaching deadlines $(x=14)$ were the two most common factors increasing anxiety, whether this be understanding the brief or feeling confident about completing assignments, illuminated by comments such as "not really understanding the assignments" (Health and Social Care Student) and being concerned about achieving low marks $(x=7)$. A further major concern $(x=15)$ was "balancing work load and family life, personal responsibilities" (Children and Young People Student.) A small body of students $(\mathrm{x}=3)$ identified as "not being good enough" (Financial and Professional Services Student), therefore suggesting low confidence and self-esteem can contribute to feelings of anxiety. Finally, teaching style and format proved to increase the anxiety of some students $(x=3)$ as they felt they did not learn much during their taught sessions: "I feel like it is all too much to take in especially in some of the lectures because of the teaching style" (Psychological Studies Student), with the volume of information overwhelming some students. This is supported by the fact that $34 \%$ of students reported preferring an interactive workshop session than a formal lecture (25\%) (Questionnaire 3).Overall anxiety levels, therefore, are influenced by students' personal circumstances and situation outside their academic studies which is often particularly complex for students who have parental or caring responsibilities and/or part-time work commitments alongside HE study. However, assessment clearly emerges as the primary factor that increases feelings of anxiety in students above and beyond all others.

\section{Factors that Decrease Anxiety}


Comparatively, a majority of students felt that their tutor $(x=28)$ had helped in reducing their anxiety. The process of having tutorials, in which students discuss their work and progression with their tutors on a one-to-one basis made students feel less anxious $(\mathrm{x}=21)$, as articulated by comments such as: "support from staff members and helping me through my assignments" (Health and Community Studies Student). While two students also explained that "just getting on with it" (Graphic Design Student) was a factor, one of the key interventions identified by students was assignment advice, with students stating that having the tutor go through, in detail, what was required in their assignments, reduced their anxiety $(x=11)$, with comments such as "more explanation and detail on what to do" (Financial and Professional Service Student). Additional input from the academic skills module may have also reduced anxiety with $92 \%$ of students rating the sessions as useful or above, in relation to supporting their academic transition $(\mathrm{x}=15)$. Provision of adequate academic support is therefore an important factor to be mindful of, especially in relation to assessment practices and literacies, yet, this does raise questions about balance in the context of the need for HE students to develop independent learning skills.

\section{Discussion}

This paper aimed to investigate three key questions: Does the transition into HE effect levels of anxiety in students? If student emotions change within the first semester of the first year, what happens? What factors influence students' emotional responses to the HE transition? Firstly, the data suggests that those students who identify as generally anxious (28\%) and those who do not identify as generally anxious (71\%) both experience negative emotions at some point, within the first semester. The Spielberger State-Trait Anxiety Inventory (Bekker and Marteau 1992) shows that the sample as a whole falls within the 'normal' range for anxiety levels, meaning that clinical anxiety is not a concern and, even with fluxes in anxiety 
to a small degree, the overall results are not of great significance. Given the specific nature of the provision in this case study, with the student body being comprised of solely students with widening participation characteristics who are entering higher education from incredibly diverse backgrounds, this overall finding would suggest that these demographic factors are, pleasingly, not influential in relation to feelings of increased anxiety during the transitionary period. Equally, it could also suggest that the approach of the instituting to supporting student transition is relatively successful. Based on the student comments in relation to tutors and academic support, the more personalised nature of HE-in-FE provision, in which tutors and students are well-known to one another and have a high proportion of 1:1 contact time, could go some way as to explaining the reasons for this situation.

Those who self-identify as generally anxious fall into the classification of anxious at the beginning of the semester but by the second point fall into the normal range (Bekker and Marteau 1992). Comparatively, those who do not self-identify as anxious are classified as being within the normal range for anxiety levels across the semester, with the score remaining constant between both testing points. As such, perhaps quite expectedly, the period of transition into $\mathrm{HE}$ is a time during which individuals who recognise as being anxious do in fact experience exacerbated feelings of anxiety. However, the extent to which this can be attributed to the transitionary experience is limited as the boundaries between state and trait anxiety are difficult to distinguish. Thus, when asked to disclose any disabilities or health concerns at the point of application and enrolment, it is important that institutions ensure mental health and wellbeing is visible and recognised as part of this process, so that students who may require additional advice and support are identified at the earliest possible moment. That said, given the pre-dominance of non-identification, there needs to be ongoing attention paid to, and awareness raising of these issues throughout the student journey. 
Secondly, in focusing on the individual emotions for those who identify as generally anxious, as the semester progresses, the levels of negative emotions remain constant while positive emotions decrease. Conversely, those who do not identify as being generally anxious become more worried and tense along with a significant difference existing between how upset students feel as the semester progresses. Nonetheless, the feelings of being content, relaxed and calm remain the same. Thus, while students do experience increasing negative emotions during this period, they do not necessarily lead to a simultaneous decrease in the positive emotions felt by the same students. However, there is clearly a change in emotions during that first semester for some students, and the data suggests that this is partially subject to whether or not students recognise as being an anxious individual. A key issue that emerges from this research is therefore one of emotional intelligence. As practitioners and $\mathrm{HE}$ institutions, is there a need to "teach" students how to manage their feelings and emotions? Whether students self-identify as being anxious or not, ensuring that they are equipped with effective strategies for managing their emotions in challenging situations may contribute to their personal development, it may also aid their progress and success through their degree and beyond.

The qualitative data suggests core factors that influence students' emotions are wholly or partially related to academic reasons and are therefore linked to the institution. Notably, students did not identify factors relating to their personal life as being particularly influential in shaping their emotions during this period, aside from the balance to be achieved between academic study and home life. This is an especially telling finding in the context of the institutional demographic and reveals that, for students with WP characteristics who are commuting, many of the social factors that can often cause emotional distress or anxiety for students are not relevant to this student population. Thus, any anxiety or negative emotional responses may be interpreted as solely influenced by factors related to the transition into and 
demands of this higher level of study. With 'assignments' 'deadlines' and 'understanding' being the central reasons identified for increased negative emotions, assessment was identified as the leading cause of increased anxiety. As such, these findings reinforce the importance of the transitionary period being recognised as just that, and a range of interventions being embedded into the curriculum (Barkham et. al. 2010; Beanlands et. al. 2017) that support the development of academic skills relevant to HE study. In particular, it is vital to enable students to understand academic language, to be able to meaningfully interpret assignment briefs, and to equip students with adequate time management skills in order to mitigate against these factors. Moreover, ensuring additional skills development and advice around assessment requirements is embedded at a later point within the semester, in line with deadlines, would appear to be welcomed by students.

Student responses as to what factors helped to decrease any feelings of anxiety illuminate a similar pattern, in that they are all intrinsic to the teaching and learning experience. The role of the 'tutor', or lecturer, is seemingly pivotal in supporting the transition and in enabling students to navigate the new expectations and demands encountered (Bore et. al. 2016). Tellingly, the word 'support' was another prominent feature in the qualitative data, thereby highlighting a critical aspect of the provision afforded by a smallcampus HE-in-FE institution. With cohort sizes typically around 20 students, with a maximum of 30 students, students in the data sample are able to access one-to-one support and to engage with their lecturers in very specific ways. Clearly, then, the importance of lecturers and students forging productive and personalised professional relationships is paramount. While this is an achievable goal in a relatively small institution, this is of course more problematic at a large HE institution with significant cohort sizes. Nonetheless, the role of the lecturer is clearly vital to facilitating a positive emotional experience for students transitioning into HE. This in itself raises further questions as to whether or not practitioners 
are equipped with the relevant knowledge and skills to support students in developing wellbeing strategies and study skills for working at this level, not just developing subject knowledge. Equally, with the issues of 'balance' (between study and personal commitments) and 'responsibility' (children and caring roles) being identified as a concern for students, would it be useful for course leaders to learn about the background of their students to allow for more understanding of a student's situation even prior to the point of induction?

Finally, in thinking about how to further mitigate against negative emotions during the transitionary period it is important that students are made aware as to what is expected in undertaking HE study (Chambers and Hassed 2014; Irwin, Miller and Kellie 2014; Martin and Richards 2012; Beanlands et al. 2017; Smalley and Winston 2010). With the emphasis on independence and autonomy, being confronted with 'deadlines' and 'understanding' timetables, module requirements and assignment briefs, it can be an unanticipated shock to many students and lead to negative responses. Yet again, the comments made by students reinforces the need for lecturers and institutions to ensure that students 'learn about learning' and are developed in terms of the skills required to study and succeed at this level. To further support a positive transitionary experience, therefore, it might be useful to understand student motivation for HE study. After all, a student's motivation may influence how determined they will be to complete assignments and progress through the degree in line with expectations. Equally, high motivation levels can help mitigate against negative emotional experiences.

\section{Conclusion}

There are some clear learning points from the findings of this exploratory study that other institutions can consider in order to support a successful and positive transition into HE study for all students, but particularly students with widening participation characteristics: 
- Engage with student health and wellbeing from the point of enquiry and cultivate honest conversations regarding the challenges, fears and anxieties about the student experience

- Provide clear guidance and signpost the range of support services available to students

- Support students to develop emotional intelligence skills and coping strategies, that build capacity to process negative feedback or experiences and develop resilience and resourcefulness, as appropriate to the demands of HE study

- Embed academic skills into the student transition in order to de-mystify jargon and unfamiliar terminology

- Ensure all students have a one-to-one tutorial with course tutors within the first few weeks of the semester

- Academic staff to be offered training and development in supporting student wellbeing and emotional intelligence skills

- Ensure relevant assessment skills support is provided at the right time in the first semester and beyond

This institutional case study has resulted in some pertinent findings regarding the student transition in a HE in FE setting, but it is important to note that given the small-scale nature of the project these findings are not generalisable. However, in any future study it is important to use a bigger sample size to ensure that normality assumptions are met and that the data can be analysed through parametric tests, thus undertaking this work in a similar institution that has a much larger student population would be useful. A further study is required to look more closely at the sequence and timing of embedding academic skills and wellbeing strategies in the student induction and transition process so as to ensure maximum impact and value. The qualitative data collected via student comments has been particularly revealing, in terms of understanding the factors that influence and shape students' emotions 
and gaining insight into student perspectives and self-identified needs during the first-year transition. Therefore, for those who do not identify as generally anxious, given the increase in more negative feelings, compared to their counterparts, interviews may be a useful tool in providing more in-depth understanding as to the consequences of the transitionary experience in the first semester on students' emotional wellbeing.

\section{References}

Abrahams, Jessie, Ann-Marie Bathmaker, Harriet Bradley, Tony Hoare, Nicola Ingram, and, Richard Waller. 2016. Social Class, Higher Education and Mobility: A Degree Generation. London: Palgrave Macmillan.

Adlaf, Edward, Andree Demers, Louis Gliksman, and, Brenda Newton-Taylor. 2001. "The prevalence of elevated psychological distress among Canadian undergraduates: Findings from the 1998 Canadian Campus Survey" Journal of American College Health 50 (2): $67-72$.

Andrews, Bernice, and John Wilding. 2004. "The Relation of Depression and Anxiety to LifeStress and Achievement in Students" British Journal of Psychology 95: 509-521.

Aspinwall, Lisa, and Shelley Taylor. 1992. "Modelling cognitive adaptation: A longitudinal investigation of the impact of individual differences and coping on college adjustment and performance” Journal of Personality and Social Psychology 63 (6): 989-1003.

Baker, Sarah. 2003. “A Prospective Longitudinal Investigation of Social Problem-Solving Appraisals on Adjustment to University, Stress, Health and Academic Motivation and Performance" Personality and Individual Differences 35: 569-591.

Balding, John, David Regis, Helen Doll, Julie Evans, Jacoby Patterson, and Sarah StewartBrown. 2000. "The health of students in institutes of higher education: An important and neglected public health problem?" Journal of Public Health Medicine 22: 492-9. 
Barkham, Michael, Bridgette Bewick, Margaret Bradley, Richard Cooke, and Kerry Audin. 2006. "Measuring, monitoring and managing the psychological well-being of first year university students" British Journal of Guidance \& Counselling 34 (4): 505-517. doi: $10.1080 / 03069880600942624$

Bewick, Bridgette, Gina Koutsopoulou, Jeremy Miles, Esther Slaa, and Michael Barkham. 2010. “Changes in Undergraduate Students' Psychological Well-Being as They Progress Through University" Studies in Higher Education 35 (6): 633-645. doi: $10.1080 / 03075070903216643$

Beanlands, Heather, Marni Binder, Jennifer Martin, Elizabeth McCay, Lori Schindel Martin, and Jasna Schwind. 2017. "Mindfulness Practice as a Teaching-Learning Strategy in Higher Education: A Qualitative Exploratory Pilot Study" Nurse Education Today 50: 92-96.

Bekker, Hilary and Theresa Marteau. 1992. "The development of a six-item short-form of the state scale of the Spielberger State-Trait Anxiety Inventory (STAI)" British Journal of Clinical Psychology 31: 301-306.

Belfield, Chris, Jack Britton, Lorraine Dearden and Laura van der Erve. 2017. "Higher Education Funding in England: Past, Present and Options for the Future" Institute for Fiscal Studies. Retrieved from: https://www.ifs.org.uk/publications/9334

Boery, Eduardo, Cezar Casotti, Ivna Freire, Bruno de Oliveira, Rafael Pereira, and Icaro Riberiro. 2018. "Stress and Quality of Life Among University Students: A Systematic Literature Review" Health Professions Education 4: 70-77.

Bore, Miles, Teresa Dluzewska, Dianne Kirby, Stuart Marlin, and Chris Pittolo. 2016. "Predictors of Psychological Distress and Well-Being in A Sample of Australian Undergraduate Students” Higher Education Research \& Development 35 (5): 869-880. doi: 10.1080/07294360.2016.1138452 
Boud, David. 1988. Developing Student Autonomy in Learning. London: Kogan Page.

Bradley, Harriet. 2017. “'Should I Stay or Should I Go?’: Dilemmas and Decisions Among UK Undergraduates" European Educational Research Journal 16 (1): 30-44. doi: $10.1177 / 1474904116669363$

Caruso, David, John Mayer, and Peter Salovey. 2004. "Emotional Intelligence: Theory, Findings, and Implications" Psychological Inquiry 15: 197-215.

Christie, Hazel. 2009. "Emotional Journeys: Young People and Transitions to University" British Journal of Sociology of Education 30 (2): 123-136. doi: $10.1080 / 01425690802700123$

Christie, Hazel, Vivienne Cree, Jenny Hounsell, Velda McCune, and Lyn Tett. 2008. “'A real rollercoaster of confidence and emotions': learning to be a university student" Studies in Higher Education 33 (5): 567-581. doi: 10.1080/03075070802373040

Cook, Anthony and Houston Lowe. 2003. "Mind the Gap: Are Students Prepared for Higher Education?" Journal of Further and Higher Education 27 (1): 53-76. doi: $10.1080 / 03098770305629$

Duckworth, A., \& Quinn, P. D. 2009. "Development and Validation of the Short Grit Scale (Grit-S)" Journal of Personality Assessment, 91 (2): 166-174. doi: 10.1080/00223890802634290.

Dweck, C. S. 2007. Mindset: The new psychology of success. NY: Random House.

Dweck, C. S. 1999. Self-theories: Their role in motivation, personality, and development. Philadelphia: Psychology Press.

Ellis, Rod. 2008. The Study of Second Language Acquisition. 2nd Ed. Oxford: OUP.

Ethics Committee of the British Psychological Society. 2009. Code of Ethics and Conduct. Leicester, UK: The British Psychological Society. 
Equality Challenge Unit. 2014a. "Equality in Higher Education: Statistical Report 2014”. Retrieved from: http://www.ecu.ac.uk/wp-content/uploads/2015/11/2015-equality-inhigher-education-student-tables.xlsx

Equality Challenge Unit. 2014b. "Equality in Higher Education: Statistical Report 2014" Retrieved from: http://www.ecu.ac.uk/wp-content/uploads/2015/11/2015-equality-inhigher-education-student-tables.xlsx

Field, Andy. 2013. Discovering Statistics Using IBM SPSS Statistics. $4^{\text {th }}$ Ed. London: SAGE Publications Ltd.

Grant, Annie. 2002. “Identifying Students' Concerns Taking a Whole Institutional Approach.” In Students' Mental Health Needs Problems and Responses, edited by Nicky Stanley, and Jill Manthorpe, 83-106. London: Jessica Kinsley.

Gudykunst, William. 2005. “An Anxiety/Uncertainty Management (AUM) theory of effective Communication" In Theorising about intercultural communication, edited by William Gudykunst, 281-322. Thousand Oaks, CA: Sage.

Hafner, Alexander, Verena Oberst, and Armin Stock. 2015. “Decreasing Students' Stress Through Time Management Training: An Intervention Study" European Journal of Psychology of Education 30: 81-94. doi: 10.1007/s10212-014-0229-2.

Hassed, Craig, and Richard Chambers. 2014. Mindful Learning: Reduce Stress and Improve Brain Performance for Effective Learning. Auckland, New Zealand: Exile Publishing Pty. Ltd.

Heckert, Teresa, Bradley Niebling, and Shannon Ross. 1999. "Sources of stress among college students" College Student Journal 33: 312-317.

Holdsworth, Clare, and Jackie Patiniotis. 2005. ““Seize that chance!”: Leaving home and Transitions to Higher Education" Journal of Youth Studies 8: 81-95. 
Irwin, Michele, John Miller, and Kelli Nigh. 2014. Teaching from the Thinking Heart: The Practice of Holistic Education. Charlotte, North Carolina: Information Age Publishing. Keane, Elaine. 2011. "Dependence-Deconstruction: Widening Participation and TraditionalEntry Students Transitioning from School to Higher Education in Ireland" Teaching in Higher Education 16 (6): 707-718. doi: 10.1080/13562517.2011.570437

Mallon, Sharon, Jill Manthorpe and Nickey Stanley. 2009. "Trapped in Transition: Findings from a UK Study of Student Suicide" British Journal of Guidance \& Counselling 37 (4): 491-433. doi: 10.1080/03069880903161427

Martin, William, and Danielle Richards. 2012. "The effects of a brief mindfulness intervention on self-compassion among undergraduate college students" Ideas and Research You Can Use: VISTAS 2012, 1: 1-6.

Misra, Ranjita, and Michelle McKean. 2000. 'College students' academic stress and its relation to their anxiety, time management and leisure satisfaction" American Journal of Health Studies 16 (1): 41-51.

Monk, Evelyn. 2004. "Student mental health. Part 2: the main study and reflections of significant issues" Counselling Psychology Quarterly 17: 33-43.

Morris, David. 2017. A beginner's guide to Longitudinal Education Outcomes (LEO) data. Retrieved from https://wonkhe.com/blogs/a-beginners-guide-to-longitudinal-educationoutcomes-leo-data/

Murphy, Helen, and Naomi Roopchad. 2003. "Intrinsic Motivation and Self-esteem in Traditional and Mature Students at a Post-1992 University in the North-east of England” Educational Studies 29 (2-3): 243-259. doi: 10.1080/03055690303278

Office for National Statistics. 2018. "Estimating Suicide Among Higher Education Students, England and Wales: Experimental Statistics". Retrieved from https://www.ons.gov.uk/peoplepopulationandcommunity/birthsdeathsandmarriages/deat 
hs/articles/estimatingsuicideamonghighereducationstudentsenglandandwalesexperiment alstatistics/2018-06-25

Porche, Demetrius. 2016. "Emotional Intelligence: A Violence Strategy” American Journal of Men's Health 10: 261.

Roberts, Ron, and Christiane Zelenyanski. 2002. "Degrees of debt" In Students' Mental Health Needs Problems and Responses, edited by Nicky Stanley, and Jill Manthorpe, 107-120. London: Jessica Kinsley.

Smalley, Susan, and Diana Winston. 2010. Fully Present: The Science, Art, and Practice of Mindfulness. Philadelphia: Da Capo Press.

Smith, Jo and Frances Howie. 2018. "Preventing Suicide in Higher Education Institutes: Opportunities and Obstacles to Successful Suicide Prevention”. Paper presented at the National Suicide Prevention Alliance Conference, London 31.

Tluczek, Audrey, Jefferey Henriques, and Rogers Brown. 2009. "Support for the Reliability and Validity of a Six-Item State Anxiety Scale Derived From the State-Trait Anxiety Inventory" Journal of Nursing Measurement 17 (1): 19-28.

Tyrell, Jeanne. 1992. "Sources of stress among psychology undergraduates" The Irish Journal of Psychology 13: 184-192.

UCAS. 2000. "Statistical Bulletin on Widening Participation", Retrieved from: http://www.ucas.com/figures/archive/widepart/.

Universities UK. 2015. "Student Mental Wellbeing in Higher Education: Good Practice Guide”. Retrieved from: https://www.universitiesuk.ac.uk/policy-andanalysis/reports/Documents/2015/student-mental-wellbeing-in-he.pdf

Van Rooijen, Karlijn. 1986. “Advanced students' adaptation to college.” Higher Education 15: 197-209. 
Watson, Joshua and April Watson. 2016. "Coping Self-Efficacy and Academic Stress Among Hispanic First-Year College Students: The Moderating Role of Emotional Intelligence" Journal of College Counseling 19 (3): 218-230.

\section{Attached items}

Appendix

Tables with Caption(s)

\footnotetext{
' All data on student demographic sourced from internal key performance indicator reports and correct at the time of writing (September 2017).
} 